BULLETIN Bulletin hispanique

HispaniQuE Université Michel de Montaigne Bordeaux

$112-2 \mid 2010$

Varia

\title{
Puntuación y stemma de La Celestina
}

Fidel Sebastián Mediavilla

\section{OpenEdition}

\section{Journals}

Edición electrónica

URL: http://journals.openedition.org/bulletinhispanique/1218

DOI: 10.4000/bulletinhispanique.1218

ISSN: $1775-3821$

\section{Editor}

Presses universitaires de Bordeaux

\section{Edición impresa}

Fecha de publicación: 31 diciembre 2010

Paginación: 509-528

ISBN: 978-2-86781-709-0

ISSN: 0007-4640

\section{Referencia electrónica}

Fidel Sebastián Mediavilla, «Puntuación y stemma de La Celestina », Bulletin hispanique [En línea] 112-2 | 2010, Publicado el 05 enero 2014, consultado el 20 abril 2019. URL : http://

journals.openedition.org/bulletinhispanique/1218; DOI : 10.4000/bulletinhispanique.1218 


\title{
Puntuación y stemma de La Celestina
}

\author{
Fidel Sebastián Mediavilla \\ Barcelona
}

Létude de la ponctuation des éditions imprimées de La Celestina et du Manuscrit de Palacio avalise les thèses suivantes: 1) le Manuscrit de Palacio fait partie d'une tradition manuscrite antérieure et séparée de l'archétype des éditions imprimées;2) l'édition de Burgos de 1499 se sépare très vite du reste de la tradition imprimée, qui procède à son tour d'un archétype commun ; 3) celle de Burgos est la seule édition qui ne dérive pas de celle corrigée par Alonso de Proaza.

El estudio de la puntuación de las ediciones impresas más antiguas de La Celestina y del Manuscrito de Palacio avala las siguientes tesis: 1. El Manuscrito de Palacio forma parte de una tradición manuscrita anterior y separada del arquetipo de las ediciones impresas. 2. La edición de Burgos 1499 se separa enseguida del resto de la tradición impresa, que procede, a su vez, de un arquetipo común. 3. La de Burgos es la única edición que no deriva de la corregida por Alonso de Proaza.

The study of punctuation in the oldest printed editions of La Celestina and of the Palacio Manuscript supports the following thesis: 1 . The Palacio Manuscript is part of a previous manuscript tradition, separated from the archetype of printed editions. 2 . The 1499 Burgos edition immediately divides from the rest of the printed tradition, which comes, in its turn, from a common archetype. 3. The Burgos edition is the only one which does not derive from the one Alonso de Proaza corrected.

Mots-clés : La Celestina - Ponctuation - Stemma.

Bulletin Hispanique, Tome 112, n 2 - décembre 2010 - p. 509 à 528. 


\section{BULLETIN HISPANIQUE}

\section{INTRODUCCIÓN}

$\mathrm{E}$ $\mathrm{N}$ un trabajo anterior abordé el estudio de la puntuación de las ediciones impresas de La Celestina, que me llevó a corroborar por medio de la puntuación algo que otros ya habían probado, esto es, que la comedia de Burgos con fecha impresa de 1499 se separa del arquetipo común a las otras dos ediciones conocidas de La Celestina de 16 actos: Toledo 1500 y Sevilla $1501^{1}$. Me propongo ahora analizar la puntuación del Manuscrito de Palacio.

En 1989 Charles Faulhaber halló en la Biblioteca del Palacio Real de Madrid, en un códice facticio, un texto que corresponde a buena parte del I auto de La Celestina, precisamente el atribuido al Antiguo Autor ${ }^{2}$. Son ocho folios que ocupan, según la numeración del tomo misceláneo, del 93 al $100^{3}$; el texto comienza en la cara 93v (23: 1), con el Siguese de presentación de la Comedia, y termina al final del folio $100 \mathrm{v}$ con las palabras $y$ en otro apartado para rremedjar, al final del folio $100 \mathrm{v}(61: 8)^{4}$.

Las cuestiones planteadas desde su aparición: autoría, lugar y papel que ocuparía en la secuenciada y compleja elaboración del texto de La Celestina siguen siendo objeto de estudio 5 .

Con el intento de obtener alguna luz en estas cuestiones, me propongo estudiar la puntuación del Manuscrito de Palacio (en adelante $M p$ ), en comparación con la de los impresos más antiguos, en concreto, las tres ediciones de la Comedia: Burgos, 1499 (B); Toledo, $1500(C)$ y Sevilla, $1501(D)$, y dos ediciones de la Tragicomedia, pertenecientes, una a las ramas altas, Zaragoza, $1507(Z)$ y otra a las ramas bajas del stemma, Sevilla, 1502,

1. F. Sebastián Mediavilla, "Las primeras ediciones de La Celestina y su puntuación», Boletín de la Real Academia Española, 83, 2003, pp. 113- 135.

2. Faulhaber lo dio a conocer tan pronto como lo hubo estudiado: "Celestina de Palacio: Madrid, Biblioteca de Palacio, MS 1520», Celestinesca, 14, 2 (1990), pp. 3-40, y «Celestina de Palacio: Roja's Holograph Manuscript», Celestinesca, 15, 1 (1991), pp. 3-52.

3. Para más detalles de la naturaleza, confección y estado del Ms. véase Patrizia Botta, «La Celestina de Palacio en sus aspectos materiales», Boletín de la Real Academia Española, 73, 1993, pp. 25-50 y 347-366.

4. Citamos el Ms. por la numeración del folio (recto o vuelto) y la línea, según la transcripción de Faulhaber, y el lugar correspondiente en la edición de La Celestina de Biblioteca Clásica, Crítica, Barcelona, 2000, especificando página y línea.

5. Puede verse el estado de la cuestión en el Prólogo de la edición de La Celestina a cargo de Francisco J. Lobera et alii de Biblioteca Clásica, ed. Crítica, Barcelona, 2000, y el artículo del mismo Lobera, «Sobre historia, texto y ecdótica alrededor del Manuscrito de Palacio», "La Celestina», V Centenario (1499-1999). Actas del congreso internacional, Cuenca, 2001. Posteriormente, Alberto Blecua, «On the Palacio Manuscrit of La Celestina», Variants, $\mathrm{N}^{\circ} 1$, 2002, pp. 175-195. 
en realidad entre 1518 y $1520(L)$, conocida como De la puta vieja. Con el fin de poder establecer las debidas comparaciones, he introducido en ordenador las variantes del texto que comparten, teniendo en cuenta que el Ms. presenta lagunas por pérdida de dos folios y otros accidentes, y que la edición de Burgos no contiene el Argumento general con el que comienzan tanto el Ms. como las demás ediciones.

\section{LA PUNTUACIÓN DEL MANUSCRITO DE PALACIO}

El Manuscrito de Palacio viene puntuado por medio de dos signos: el punto y la barra (ésta, con un trazo que oscila entre una recta oblicua [/] y una curva semejante al paréntesis inicial [(], y que transcribimos, con Faulhaber, con el tipo 'barra' [/]. Llama la atención la ausencia de signo de interrogación (la comedia de Burgos es la única edición impresa que tampoco lo trae). Véase en un cuadro comparativo la distribución de signos de puntuación del manuscrito y de las ediciones:

\begin{tabular}{|l|c|c|c|c|c|c|}
\hline & $\mathrm{Mp}$ & $\begin{array}{c}\text { Burgos } \\
1499 \\
B\end{array}$ & $\begin{array}{c}\text { Toledo } \\
1500 \\
C\end{array}$ & $\begin{array}{c}\text { Sevilla } \\
1501 \\
D\end{array}$ & $\begin{array}{c}\text { Zaragoza } \\
1507 \\
Z\end{array}$ & $\begin{array}{c}\text { Sevilla } \\
{[1502} \\
L\end{array}$ \\
\hline Punto & 431 & 4284 & 2716 & 3271 & 3186 & 3132 \\
\hline Dos puntos & 0 & 2905 & 4459 & 3839 & 3881 & 4429 \\
\hline Barra & 89 & 0 & 201 & 317 & 2585 & 0 \\
\hline Coma & 0 & 0 & 0 & 0 & 0 & 0 \\
\hline Interrogante & 0 & 0 & 708 & 745 & 833 & 794 \\
\hline Admiración & 0 & 0 & 0 & 0 & 0 & 0 \\
\hline Paréntesis & 0 & 0 & 0 & 0 & 3 & 21 \\
\hline Calderón & 0 & 15 & 62 & 67 & 29 & 57 \\
\hline Total signos & 520 & 7204 & 8146 & 8239 & 10517 & 8433 \\
\hline Palabras & 4307 & 53428 & 54831 & 55206 & 65568 & 69433 \\
\hline $\begin{array}{l}\text { Proporción } \\
\text { signo/palabras }\end{array}$ & $1 / 8,28$ & $1 / 7,41$ & $1 / 6,73$ & $1 / 6,70$ & $1 / 6,23$ & $1 / 8,23$ \\
\hline
\end{tabular}

Punto y barra comparten, indiscriminadamente en $M p$, la misión de acabar frase o separar partes dentro de ella. La puntuación del texto es muy defectuosa. Son muy abundantes los errores de puntuación por exceso o por defecto: algunas interrupciones inoportunas, pero, sobre todo, ausencia 
de puntuación cuando ésta es menester para acabar frase y separarla de la siguiente. Obsérvese en el cuadro precedente cómo la frecuencia de signos es notablemente inferior en el manuscrito respecto de los impresos más antiguos.

La coincidencia de lugares puntuados por $M p$ y las ediciones impresas -comedias y tragicomedies- es del 60,38\%. La coincidencia con sólo las comedias es del 65,76\%).

\section{Puntuación contrastada de $M P$ Y LAS EDICIONES IMPRESAS}

Las abundantes variantes de puntuación se distribuyen según el siguiente cuadro:

\begin{tabular}{|c|c|c|c|}
\hline$M p B C D Z L$ & 314 & $-B C D Z L$ & 41 \\
\hline$+B C D Z L$ & 113 & $-B C D Z$ & 4 \\
\hline$+B C D Z$ & 47 & $-B D Z L$ & 1 \\
\hline$+B D Z L$ & 11 & $-C D Z L$ & 4 \\
\hline$+C D Z L$ & 15 & $-C D Z$ & 1 \\
\hline$+C D Z$ & 18 & $-C D L$ & 0 \\
\hline$+C D L$ & 1 & $-D Z L$ & 0 \\
\hline$+D Z L$ & 6 & $-B Z L$ & 0 \\
\hline$+B Z L$ & 13 & $-B D L$ & 3 \\
\hline$+B D L$ & 1 & $-B C L$ & 4 \\
\hline$+B C L$ & 2 & $-B C D$ & 49 \\
\hline$+B C D$ & 7 & $-B C Z$ & 1 \\
\hline$+B C Z$ & 20 & $-B D Z$ & 2 \\
\hline$+B D Z$ & 1 & $-Z L$ & 2 \\
\hline$+Z L$ & 24 & $-B C$ & 25 \\
\hline$+B C$ & 2 & $-B D$ & 0 \\
\hline$+B D$ & 1 & $-B Z$ & 1 \\
\hline$+B Z$ & 2 & $-B L$ & 2 \\
\hline$+B L$ & 2 & $-C D$ & 6 \\
\hline$+C D$ & 5 & $-C Z$ & 1 \\
\hline$+C Z$ & 9 & $-C L$ & 0 \\
\hline$+C L$ & 0 & $-D Z$ & 0 \\
\hline$+D Z$ & 6 & $-D L$ & 2 \\
\hline$+D L$ & 1 & $-L$ & 22 \\
\hline$+L$ & 3 & $-Z$ & 4 \\
\hline$+Z$ & 54 & $-D$ & 3 \\
\hline$+C$ & 6 & $-C$ & 22 \\
\hline$+D$ & 1 & $-B$ & 7 \\
\hline$+B$ & 2 & & \\
\hline
\end{tabular}

Dejamos para el capítulo $\mathrm{V}$ la interpretación de estos datos junto con los que se exponen a continuación. 


\section{ERrores COMPARTIDOS}

Después de averiguar los datos cuantitativos, procede comentar los errores compartidos. No hablamos de errores comunes en el sentido que tienen en la teoría lachmanniana, por cuanto todos los que presenta nuestro texto son fácilmente sanables, pero hablaremos de errores de puntuación cuando se trate de una ausencia de separación entre frases completas, y especialmente cuando falte una señal en el tránsito de diferentes modalidades oracionales: de exhortativa a interrogativa, de interrogativa a aseverativa, etc. También notaremos de error los casos -y son los menos- en que una puntuación interrumpe el sentido y la curva de entonación de una frase al tiempo que contraviene su sintaxis. La coincidencia en una puntuación flagrantemente defectuosa, y más si se da en un número considerable de ocasiones, establece parentesco entre los testimonios de una tradición textual, lo mismo que la sanación por parte de unos donde otros dejan de hacerlo.

Según estos criterios, observamos que los errores de puntuación de $M p$ son compartidos o corregidos de acuerdo con la siguiente distribución (debajo del texto que se cita, se reproduce el lugar correspondiente en la edición de Biblioteca Clásica):

\section{IV.1 Correcciones unánimes de los impresos $(B C D Z L)$}

1. c. vete de Ay no me hables sy no quiça Antes que venga la muerte quespero mjs manos cabsaran tu ARebatada fyn (94v: 20).

CALISTO. ¡Vete de ahí! No me hables! Si no, quizá ante del tiempo de mi rabiosa muerte mis manos causarán tu arrebatado fin (30: 4).

El punto que insertan las ediciones después de hables es exigido por tratarse de final de frase, pero es todavía más exigible, si cabe, por razón de la entonación, por cuanto supone el paso de la imperativa de la primera frase a otra enunciativa. En cambio, el punto que las ediciones modernas colocan después de ahi, entre las dos oraciones exhortativas, no lo trae ninguna de las ediciones cotejadas.

2. S. no puede ser segund pienso yr conmjgo el que contigo queda.o desaventura . o supito mal qual fue tan contrario conteçimjento que Asy tan presto Robo ellalegria deste onbre y lo ques peor junto conella el seso . dexarlee solo / o entrare Alla sy le dexo matar se a. sy entro matar me a (94v: 27). 
SEMPRONIO. No creo, según pienso, ir conmigo el que contigo queda. ¡Oh desventura! ¡Oh súbito mal! ¿Cuál fue tan contrario acontecimiento que ansí tan presto robó el alegría deste hombre, y lo que peor es, junto con ella el seso? ¿Dejarle he solo o entraré allá? Si le dejo, matarse ha; si entro allá, matarme ha (30:10).

He aquí una situación semejante a la anterior, en que el punto debe marcar el cambio de modalidad oracional: se cierra una interrogación y comienza una enunciación.

3. pero sy se mata syn otro testigo yo quedo / obljgado A dar cuenta de su vida. qujero entrar. mas puesto que entre no quiere consolacion njn consejo asaz. es señal mortal non querer sanar (95r: 6).

Pero si se mata sin otro testigo, yo quedo obligado a dar cuenta de su vida. Quiero entrar. Mas puesto que entre, no quiere consolación ni consejo. Asaz es señal mortal no querer sanar (30: 17).

Aquí el error de puntuación no afecta al tipo de entonación, pero entorpece la intelección del texto, que queda doblemente deturpado por el punto después de asaz, que corrigen las cinco ediciones. Así como otros descuidos podrían ser los propios de un redactor distraído, aquí se evidencia el copista poco atento. Una cosa es dejar de puntuar (muchos escritores lo han venido haciendo hasta nuestros días, como otros descuidan los acentos y otra distinta que un escritor puntúe contra el sentido de lo que se quiere decir: éste es error de copista.

4. c [^que estas murmurando] di lo que dizes no temas (95v: 13).

CALISTO. ¿Qué estás murmurando, Sempronio?

SEMPRONIO. No digo nada.

CALISTO. Di lo que dices; no temas (33: 10).

El manuscrito trae en este pasaje una redacción distinta de la tradición impresa: el escriba interpola lo señalado entre corchetes, pero el modelo de los impresos es ligeramente más complejo (¡simplificó el copista intencionadamente a tenor del espacio entre líneas al corregir según la segunda redacción que utilizó?). Se echa en falta un punto necesario, también aquí, por razones no sólo sintácticas sino de entonación, pues termina una oración interrogativa y comienza una exhortativa.

5, 6. c. commo yo telo dire mayor es la llama que tura ochenta años que nola que en vn dia pasa (95v: 16, 17). 
CALISTO. ¿Cómo? Yo te lo diré. Mayor es la llama que dura ochenta ańos que la que en un día pasa (33: 16).

Inexcusables los dos puntos que sí trae la tradición impresa. El primero, para cerrar una oración interrogativa. El segundo lo exigen también a un tiempo el sentido, la sintaxis y la entonación.

7, 8. S. Algo es lo que digo amas ha deyr este fecho no basta loco syno erege (95v: 26, 27).

SEMPRONIO. (Algo es lo que digo; a más ha de ir este hecho. No basta loco, sino hereje.) (34: 4).

La necesidad de puntuar en ambos sitios es atendida por todos los impresos.

9. considera que sesito esta debaxo de aquellas luengas y delgadas tocas . que pensamjentos so aquellas gorgueras que falsedades so aquel fausto so aquellas largas \& abtorizadas Ropas . que jnperfiçion que aluañares debaxo que tenplos pintados desuare por ellas es dicho . arma del diablo cabeça de pecado destruyçion de parayso (96v: 6).

Considera qué sesito está debajo de aquellas grandes y delgadas tocas, qué pensamientos so aquellas gorgueras, so aquel fausto, so aquellas largas y autorizantes ropas, qué imperfición, qué albañares debajo de templos pintados. Por ellas es dicho "Arma del diablo, cabeza de pecado, destruición de paraíso” (40:11).

El extraño desuare pertenece a uno de los pasajes afectados por la mancha de grasa que oscurece la reproducción de Faulhaber. Botta, acudiendo al original, aclara esta lectura dudosa, leyendo defuera, que es perfectamente coherente con el texto ${ }^{6}$. La tradición impresa lo elimina (¿no lo entendió tampoco?).

10. S. alos que las vençieron mjra que Remjdases que no Alos que dellas fueron vençidos. guarda sus engaños sabes que hazen (96v: 169).

SEMPRONIO. A los que las vencieron querría que remedases, que no a los que dellas fueron vencidos. Huye de sus engaños. ¿¿Sabes qué hacen? (41: 8).

6 Cf. op. cit., p. 37. Leen del mimo modo Lobera, «Aparato crítico», p. 384, y Blecua, op. cit., p. 180. 
Una vez más, el punto se hace doblemente necesario por el paso de una oración exhortativa a otra interrogativa. Las ediciones puntúan conveniente y unánimemente.

11, 12, 13. c [^pero no de Melibea] en todo lo que me as gloriado sin proposicion njn conparacion se aventaja melibea [ ${ }^{*}$ miras] la nobleza \& antiguedad desu linajel el grandjsimo apa[...] el excelentisimo yngenjo I las Resplandeçientes virtudes la a [...] la ynefable gracia / la soberana fermosura dela qual te [*ruego] me dexes hablar vn poco por que aya algund Refrigerio [*y] lo que te dixere / sera delo descubierto que sy delo otro oculto hablar sopiera / no nos fuera nesçesario / tan miserable mente altercar estas Razones / (97r: 16, 17).

CALISTO. Pero no de Melibea, y en todo lo que me has gloriado, Sempronio, sin proposición ni comparación se aventaja Melibea ¿Miras la nobleza y antigüedad de su linaje, el grandísimo patrimonio, el excelentísimo ingenio, las resplandecientes virtudes, la altitud y inefable gracia, la soberana hermosura, de la cual te ruego me dejes hablar un poco, por que haya algún refrigerio? Y lo que te dijere será de lo descubierto, que si de lo otro oculto yo hablarte sopiera, no nos fuera necesario altercar tan miserablemente estas razones (43:3).

El comienzo del parlamento está añadido por el escriba entre líneas. Por lo demás, en este pasaje, en el que no se aprecian variantes de redacción, la puntuación deficiente del manuscrito es corregida por la tradición impresa.

14. S. calla Señora mja . tu piensas que la distançia del lugar es poderosa de apartar el entrañable amor el fuego que esta en mj coraçon do yo vo comjgo va comjgo esta (98r: 4).

SEMPRONIO. Calla, señora mía. ¿Tú piensas que la distancia del lugar es poderosa de apartar el entrañable amor, el fuego que está en mi corazón? Do yo vo, conmigo vas, conmigo estás (49: 12).

Inexcusable el punto entre interrogación y afirmación. Los cinco señalan, además, de una manera u otra la separación entre conmigo vas y conmigo estás, siguiendo otra redacción, con cambio de sujeto.

15. mas di que pasos suenan arriba. qujen vn mj enamorado (98r: 6).

[SEMPRONIO] Mas di, ¿qué pasos suenan arriba?

ELICIA. ¿Quién? Un mi enamorado (49: 14). 
Paso de interrogativa a enunciativa corregido por los impresos de acuerdo con su arquetipo.

16. Ce. parta dios hijo contigo delos suyos que no sin meritos lo hara si qujera por que as piedad desta pecadora de vjeja pero di no te detengas que la amjstad que entre ti \& mj se afirma. no ha menester preanbulos ni correlarios nj aparejos para ganar voluntad abrevja y ven al hecho que vanamente se dize por muchas palabras lo que por pocas se puede entender (98rv: 10).

CELESTINA. Parta Dios, hijo, de lo suyo contigo, que no sin causa lo hará, siquiera porque has piedad desta pecadora de vieja. Pero di, no te detengas, que la amistad que entre ti y mí se afirma no ha menester preámbulos ni correlarios ni aparejos para ganar voluntad. Abrevia y ven al hecho, que vanamente se dice por muchas palabras lo que por pocas se puede entender (51: 12).

Pausa entre dos oraciones exhortativas, cada una de ellas completa tanto desde el punto de vista sintáctico como desde el fonológico. Puntúan convenientemente las ediciones en su redacción que, en este pasaje, sólo difiere en una palabra, causa por meritos.

17, 18. p. por que señor te matas por que te congoxas ni atormentes tu piensas ques vituperio enlas orejas desta el nonbre que la llame non lo creas $(99 \mathrm{r}: 8,9)$.

PÁRMENO. ¿Por qué, señor, te matas? ¿Por qué, señor, te congojas? ¿Y tú piensas que es vituperio en las orejas désta el nombre que la llamé? No lo creas (53: 3).

Los dos vacíos de puntuación señalados reclaman sendos puntos que marquen el final de dos oraciones interrogativas. El que debería haber también detrás de matas lo traen todas las ediciones menos $B$.

19. y demas desto en toda esta cibdad es nonbrada y por este titulo conosçida si entre çient mugeres va y alguna dize puta vieja. luego sin ningun enpacho buelue la cabeça y rresponde con alegre cara (99r: 13).

Y demás desto, es nombrada y por tal título conocida. Si entre cien mujeres va y alguna dice: “¡Puta vieja!”, sin ningún empacho luego vuelve la cabeza y responde con alegre cara $(53: 6)$. 
Con alguna variante de redacción, las ediciones puntúan adecuadamente allí donde el manuscrito deja de hacerlo.

20. al perder enlos tableros / luego suenan sus loores toda cosa que son haze a do qujera que ella esta. el tal nonbre rrepresenta (99v: 2).

$\mathrm{Al}$ perder en los tableros, luego suenan sus loores. Toda cosa que son hace, a doquiera que ella está, el tal nombre representa (53:20).

En este lugar, $M p$ proporciona la redacción correcta (toda cosa que son haze... el tal nombre representa), que no está afectada por un error común de toda la tradición impresa antigua: todas cosas que son hazen el tan nombre representa $(B, C, Z, P, H, L)$; todas cosas que son hazen el tal nombre representan $(D, K, L, M)^{7}$. En cambio, la puntuación señalada la traen correctamente donde el manuscrito la descuida.

21. era el primero ofçio cobertura delos otros. so color del qual muchas moças destas serujentas entravan ensu casa alabrarse y alabrar camjsas. gorgeras . y otras muchas cosas . y njnguna vjnje aella. sin torrezno trigo . harina. jarro de vjno y delas otras proujsiones que podian hurtar a sus amas. y de avn otros hurtillos de mas caljdad. alli se encubrian asaz era muy amiga de estudiantes y despenseros y moços de abades (99v: 26).

[PÁRMENO] Era el primero oficio cobertura de los otros, so color del cual muchas mozas destas sirvientes entraban en su casa a labrarse y a labrar camisas y gorgueras y otras muchas cosas. Ninguna venía sin torrezno, trigo, harina o jarro de vino y de las otras provisiones que podían a sus amas hurtar; y aun otros hurtillos de más cualidad allí se encubrían. Asaz era amiga de estudiantes y despenseros y mozos de abades (54: 18).

Las cinco ediciones ponen punto donde el sentido lo exige. $Y$ omiten el punto inoportuno que sigue a caljdad, excepto $Z$ que interpone una barra [/] con sentido eufónico.

\section{IV.2 Errores compartidos por $M p$ con $B$ frente A $C, D, Z, L$}

Burgos comparte puntuación defectuosa en ocasiones donde $C$ y $D$ y las tragicomedias corrigen juntas:

7 Cf. F. J. Lobera, «Stemma», p. CCXXIII. 
1. c. Asy los diablos te ljeven Asy muerte desastrada mueras Asy perpetuo tengas el tormento que yo traygo ques peor commo dizes verdad (94v: 13)

CALISTO. ¡Ansí los diablos te ganen! ¡Ansí por infortunio arrebatado perezcas o perpetuo intolerable tormento consigas, el cual en grado incomparablemente a la penosa y desastrada muerte que espero traspasa! (29: 1).

En este pasaje puntúan convenientemente $C, D, Z y L . B$ comparte error con $M p$.

2. c. saca la vela y dexa la tinjebra Aconpañar Al triste y al desdichado la ceguedad (94v: 16).

CALISTO. Cierra la ventana y deja la tiniebla acompañar al triste, y al desdichado la ceguedad (29: 7).

Corrigen de un mismo modo las tragicomedias junto con $C$ y $D$.

3. o supito mal qual fue tan contrario conteçimjento que Asy tan presto Robo ellalegria deste onbre (94v: 24).

¡Oh súbito mal! ¿Cuál fue tan contrario acontecimiento que ansí tan presto robó el alegría deste hombre, y lo que peor es, junto con ella el seso? (30: 11).

También en este caso corrigen todos menos $B$.

4. por eso qujerome Agora estar vn poco . sy entre tanto se muere muera qujça con algo me dare que otro nolo [...] con que mude el pelo malo (95r: 15).

Por eso quiérome sofrir un poco. Si entre tanto se matare, muera. Quizá con algo me quedaré que otro no lo sabe con que mude el pelo malo (31: 10).

Donde termina una oración exhortativa (muera), comienza una dubitativa (qujça). La ausencia de punto es error de puntuación, que comparte $B \mathrm{y}$ corrigen $C, D, Z$ y $L$. 
5. [...] constituydas . se sometieron Alos pechos y Resollos de viles y canpestres azemjleros (96r: 1).

[desesperas de alcanzar una mujer, muchas de las cuales, en grandes estados] constituidas, se sometieron a los pechos y resollos de viles acemileros (38: 7).

Aquí, por el contrario es $M p$ quien inserta un punto errado que comparte $B$, mientras corrigen las otras comedias, y también las tragicomedias.

6. S. lo de tu aguela conel xjmjo fue habljlla testigo es el cuchillo de tu Aguelo caljsto (96r:5).

SEMPRONIO. Lo de tu abuela con el jimio ¿̨hablilla fue? Testigo es el cuchillo de tu abuelo (38: 12).

Falta un punto al final de frase, que corrigen $C$ y $D$ (y las tragicomedias), mientras $B$ transmite el mismo error.

7. S. no se sy so necio $n[\ldots]$ escoziote lee los estoriales estudia los filosofos mira los poetas llenos estan los ljbros de sus viles enxenplos (96r: 7).

SEMPRONIO. ¿Escociote? Lee los historiales, estudia los filósofos, mira los poetas. Llenos están los libros de sus viles y malos enjemplos (39: 2).

En el paso de una interrogativa a una imperativa es preciso puntuar: yerran de un mismo modo $M p$ y $B$ frente a las otras comedias y a las tragicomedias.

8. guarda sus engaños sabes que hazen cosa es dificil entendellas (96v: 16).

Huye de sus engaños. ¿Sabes qué hacen? Cosa que es difícil entenderlas (41:9).

Sólo Burgos comparte este error en final de una interrogativa.

9. y lo que te dixere / sera delo descubierto (97r: 22).

Y lo que te dijere será de lo descobierto (43: 8).

El sujeto (lo que te dixere) está indebidamente separado de su verbo (sera), en $M p$ y en $B$, frente al resto de testimonios. 
10. c. comjenço por los cabellos ves tu las madexas de oro delgado que hilan en Arabia (97v:4).

CALISTO. Comienzo por los cabellos. ¿Vees tú las madejas del oro delgado que hilan en Arabia? (44: 5).

Falta un punto en $M p$ y $B$ que corrigen en cambio los otros impresos.

11. S. madre mja . bjen ternas confiança que no te burlo . toma el manto y vamos que por el camjno sabras lo que si aqui me tardase en dezirte ynpediria tu provecho y el mjo (98r: 24).

SEMPRONIO. Madre mía, bien ternás confianza y creerás que no te burlo. Toma el manto y vamos, que por el camino sabrás lo que si aquí me tardase en decirte impediría tu provecho y el mío (50: 16).

En este caso no podemos hablar de error en sentido propio, aunque sí de un modo inusual de puntuar en La Celestina, que de ordinario no separa los vocativos. Aquí, la puntuación inhabitual de $M p$ la comparte $B$, mientras los demás impresos la eliminan, de acuerdo con el modo habitual de proceder en el texto con los vocativos.

$12,13,14$. p. por que señor te matas por que te congoxas ni atormentes tu piensas ques vituperio enlas orejas desta el nonbre que la llame non lo creas que asi se glorifica enle oyr commo qual qujer buen maestro ensu arte lo commo tu quando oyes diestro cavallero es caljsto (99r:7).

PÁRMENO. ¿Por qué, señor, te matas? ¿Por qué, señor, te congojas? ¿Y tú piensas que es vituperio en las orejas désta el nombre que la llamé? No lo creas, que ansí se glorifica en el oír, como tú cuando dicen: "Diestro caballero es Calisto" (43: 3).

En esta sucesión de interrogativas seguida de una oración enunciativa compleja, $M p$ acumula omisiones de puntos necesarios para la correcta intelección -cuanto más, para la lectura correcta en voz alta- que en unos casos corrigen todas las ediciones, y en otros, los señalados, $B$ comparte error con el manuscrito. 


\section{IV.3 $B$ Lee con $M p$ frente a $C$ y $D$}

Hallamos otros lugares en los que leen -unas veces bien, la mayor parte mal- $M p$ con $B$, frente a $C$ y $D$, sin que los sigan $Z$ y $L$ conjuntamente. Son los siguientes:

1. asaz. es señal mortal non querer sanar. con todo quiero le dexar vn poco . desbrave . madure (95r: 7).

Asaz es señal mortal no querer sanar. Con todo, quiérole dejar un poco desbrave, madure (31:2).

Con dos puntuaciones diferentes, se proponen dos redacciones: $M p$ y $B$, con punto, darían valor de desiderativa a la expresión desbrave. madure, terminada la anterior quiero le dexar vn poco. En cambio, la redacción de C y $D$, al eliminar el punto, proponen una oración subordinada sustantiva asindética: quierole dexar vn poco [que] desbrave, [que] madure. Probablemente es mejor y más autorizada la primera.

2, 3. por eso qujerome Agora estar vn poco . sy entre tanto se muere muera qujça con algo me dare que otro nolo [...] con que mude el pelo malo (95r: 15).

Por eso quiérome sofrir un poco. Si entre tanto se matare, muera. Quizá con algo me quedaré que otro no lo sabe con que mude el pelo malo (31: 10).

Aquí $C$ y $D$ corrigen poniendo un punto y quitando otro donde $B$ lee con $M p$ de modo diferente (el punto después de muera lo incorporan todas las ediciones).

4. la Redondeza y forma delas pequeñas tetas qujen telo podra figurar (97v: 17).

La redondeza y forma de las pequeñas tetas, ¿quién te las podría figurar? (45: 1).

Dos modos de puntuar y de pronunciar la interrogativa, que proponen respectivamente $M p$ y $B$ por un lado y las otras comedias y las tragicomedias, por otro.

5. entodos los ayuntamjentos de gentes con ella pasan tienpo si esta entre los onbres no pueden al dezir si pasa por los perros . aquello suena 
su ladrjdo si esta çerca las aves otra cosa no cantan . si cerca las bestias rrebuznando dizen puta vieja si cerca los ganados balando la pregonan (99r: 17).

en todos los ayuntamientos de gentes, con ella pasan tiempo. Si pasa por los perros, aquello suena su ladrido; si está cerca las aves, otra cosa no cantan; si cerca los ganados, balando lo pregonan; si cerca las bestias, rebuznando dicen: "Puta vieja" (53: 10).

$C$ y $D$ yerran: omiten juntas el punto señalado en la sucesión de condicionales.

6, 7. Las vnas madre aca . las otras madre aculla .-2 cata la vjeja . ya vjene el ama.-123 de todas muy conosçida (100r: 11).

Las unas "Madre acá", las otras "Madre acullá", "Cata la vieja”, "Ya viene el ama"; de todas muy conocida (56:1).

$C$ y $D$ omiten juntas el signo de puntuación en esta serie de yuxtapuestas que sí puntúa $B$ con $M p$ (las tragicomedias también puntúan).

\section{IV.4 $Z$ Y $L$ leen con $B$ separándose de $C$ y $D$}

No dejan de tener su interés las lecturas en que, independientemente de $M p$, las tragicomedias antiguas leen con $B$, frente a una lectura distinta $y$ unánime de las otras dos comedias. Así:

1. o supito mal qual fue tan contrario contecimjento (94v: 24).

¡Oh súbito mal! ¿Cuál fue tan contrario acontecimiento que ansí tan presto robó el alegría deste hombre, y lo que peor es, junto con ella el seso? (30: 11).

Este error es compartido por $C y$ y mientras que $B, Z$ y $L$ corrigen colocando un punto al final de un vocativo al que se formula una interrogación.

2-7. qujen tiene dentro del pecho ynjurias pecados sospechas agujjones paz guerra tregua Amor y enemjstad todo en vna cabsa (95v: 5).

quien tiene dentro del pecho aguijones, paz, guerra, tregua, amor, enemistad, injurias, pecados, sospechas, todo a una causa? (32: 13). 
En los lugares señalados en esta sucesión de sustantivos puntúan $B, Z$ y $L$, frente a $C$ y $D$ que no lo hacen.

8. c. ves quanto mas me dizes y mas ynconvenjentes me pones mas la qujero no se ques (96v: 25).

CALISTO. ¿Vees? Mientra más me dices y más inconvenientes me pones, más la quiero. No sé qué se es (42:4).

Este final de frase lo marcan solamente $B, Z_{\mathrm{y}} L$.

9, 10. en todos los ayuntamjentos de gentes con ella pasan tienpo si esta entre los onbres no pueden al dezir si pasa por los perros. aquello suena su ladrjdo si esta cerca las aves otra cosa no cantan. si cerca las bestias rrebuznando dizen puta vieja si cerca los ganados balando la pregonan (99r: 17).

en todos los ayuntamientos de gentes, con ella pasan tiempo. Si pasa por los perros, aquello suena su ladrido; si está cerca las aves, otra cosa no cantan; si cerca los ganados, balando lo pregonan; si cerca las bestias, rebuznando dicen: "Puta vieja" (53: 10).

Dos puntos necesarios que marcan $B, Z$ y $L$ y que, en cambio, $C$ y $D$ omiten, en este caso, del mismo modo que $M p$.

\section{Conclusiones}

Toca ahora interpretar los datos acumulados.

$\mathrm{Ni}$ que decir tiene que la cantidad de lugares comúnmente puntuados por $M p$ y las ediciones antiguas (60,38 \%), los demuestran hijos de un modelo común, el original.

A partir de aquí, según los datos cuantitativos y cualitativos de la puntuación de uno y otras, se pueden extraer las siguientes consideraciones:

1. $M p$ puntúa de modo distinto que la tradición impresa $(B C D Z L)$ en 154 lugares (el 30\% del total de la puntuación del Ms). Además presenta en solitario 21 errores de puntuación que corrigen de modo unánime todos los impresos (supra, IV. 1). Es lícito concluir que desde un primer momento $M p$ se separa de la rama que dará lugar tanto a las comedias como a las tragicomedias. En el origen del stemma: 


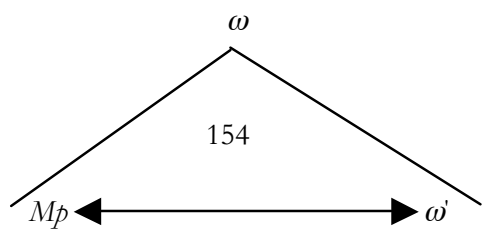

(21)

2. $B$ comparte puntuación con $M p$ separándose de otra opción unánime de $C D Z L$ en 19 ocasiones, 14 de las cuales son errores compartidos por los primeros y correcciones de los segundos (IV. 2). De ello se debe concluir que $B$ se separa enseguida del resto de la tradición impresa, y que tanto las otras comedias, $C$ y $D$, como las tragicomedias, proceden de un arquetipo común, ya separado de $B$. Además, $B$ lee con las dos tragicomedias $(Z$ y $L)$, frente a otras lecturas conjuntas de $C$ y $D$ (IV. 3). Todo lo cual se traduce en el siguiente paso del stemma:

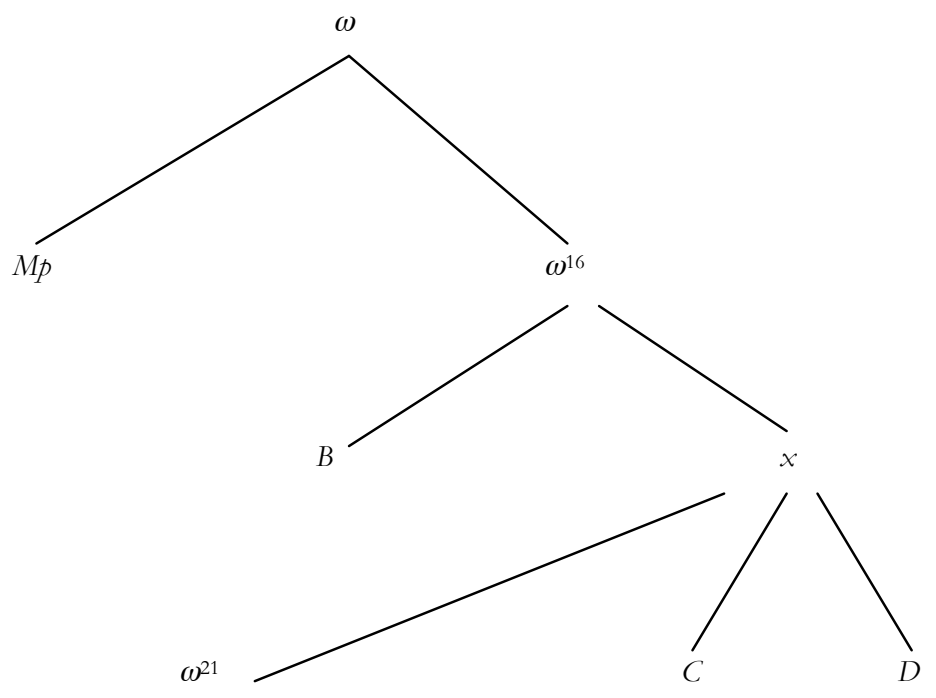


3. Errores tan frecuentes y deturpadores en el Ms. revelan que no están allí por mano de autor, sino de copista sin iniciativa y a veces distraído ${ }^{8}$. En efecto, un escritor descuida con frecuencia el puntuar; un copista culto introduciría fácilmente correcciones al original -¿quién sabe si el modelo de que copió venía todavía peor puntuado?-; lo que es inconcebible es que un amanuense pudiera copiar de un texto medianamente bien puntuado -como son los impresos conocidos- y eliminara de manera recalcitrante la oportuna y aun necesaria puntuación. Por tanto, es preciso concluir que el Manuscrito de Palacio forma parte de una tradición manuscrita anterior y separada del arquetipo de los impresos. Las interpolaciones (verdaderas correcciones) de frases completas, añadidas por el mismo u otro escriba, en consonancia con las ediciones impresas, pueden avalar la corrección del texto a la vista de otra versión corregida, distinta de la primera que se copió.

4. El sistema de puntuación de $M p$ consta tan solo de dos signos de puntuación (el punto y la barra) y carece del absolutamente necesario interrogante. No resulta insólito para un manuscrito, sea autógrafo o apógrafo. Sí lo es, en cambio, encontrarlo en un impreso, la edición burgalesa de la Comedia, que se atiene también a dos solos signos de puntuación: en este caso, el punto y los dos puntos. Si se quiere, existiría un cierto apoyo teórico para justificarlo en las Introducciones de Nebrija, donde se aconseja usar tan sólo del colon y la comma, aunque concede que «el signo de interrogación es pertinente al final de las frases que pronunciamos como interrogativas»? Es verdaderamente chocante, y de muy señalada importancia para nuestra investigación, el que, de manera singular, la edición de Burgos se separe de todas las demás conocidas por ir puntuada exclusivamente con dos signos, excluyendo completamente los interrogantes ${ }^{10}$. Lo cual nos viene a decir, no sólo que $B$ se separa de $C$ y $D$, cosa que ya conocemos por muy diversas vías, sino que, además, la distingue del resto de impresos el hecho de no estar afectada por la corrección de Alonso de Proaza, que tuvo lugar, obviamente, antes de la de Toledo, 1500 y Sevilla, 1501, que se atienen a ella.

Se ha escrito mucho acerca de si los paratextos que acompañan a los impresos a partir de la edición toledana de la Comedia, que no constan en

8. Acerca de la posibilidad de que hayan intervenido en $M p$ dos copistas, véase el artículo citado de Patrizia Botta.

9. Cf. F. Sebastián Mediavilla, Puntuación, humanismo e imprenta en el Siglo de Oro, Academia del Hispanismo, Vigo, 2007, p. 23-24 y 87-88.

10. Acerca del sistema de puntuación de otras ediciones de la Tragicomedia impresas en el XVI, véase nuestro artículo «Las primeras ediciones de La Celestina y su puntuación», especialmente, p. 116. 
el único ejemplar que se conserva de $B$, podían haber acompañado a éste en unos folios perdidos ${ }^{11}$. Por lo que toca a los preliminares se puede seguir especulando, pero, por lo que respecta a las octavas finales del corrector Alonso de Proaza, éstas ni están ni han podido estar nunca, por cuanto lo que en ellas declara el corrector sólo se compadece con el modo de puntuar de las ediciones que las incluyen, y desautoriza, en cambio, la deficiente puntuación de la burgalesa que deja desprovisto de interrogantes a un texto precisamente dialogado. En la cuarta de sus octavas, el humanista asturiano declara cómo ha de actuar el lector para hacerse entender de quienes le escuchen relatar-recitar la comedia:

Si amas y quieres a mucha atención leyendo a Calisto mover los oyentes, cumple que sepas hablar entre dientes: a veces con gozo, esperanza y pasión, a veces airado, con gran turbación. Finge, leyendo, mil artes y modos; pregunta y responde por boca de todos llorando y riyendo en tiempo y sazón (352: 18).

Este menester requiere disponer de un texto claro y "bien puntado", que es justamente la tarea que asumió y de la que se jacta justamente en la última estrofa que cierra el libro a modo de colofón:

El carro Febeo, después de haber dado mil y quinientas vueltas en rueda, ambos entonce los hijos de Leda a Febo en su casa tenién posentado, cuando este muy dulce y breve tratado, después de revisto y bien corregido, con gran vigilancia puntado y leído, fue en Salamanca impreso acabado (354:4).

La edición que corrigió y puntuó, y que seguirían con más o menos variantes todas las demás ediciones, con inclusión de las octavas declaratorias

11. La edición de Toledo de 1500, impresa por Pedro Hagenbach, es la primera de las conocidas que incluye en los preliminares del texto una carta «del autor a un su amigo» anónimo y once octavas acrósticas que revelan el nombre del autor, y, al final del libro, seis octavas más, compuestas por un humanista profesional, Alonso de Proaza, que declara haber ejercido de corrector de la edición. Acerca de la posibilidad de que se hubieran perdido en el ejemplar conservado de la edición burgalesa, véase F. Rico y F. J. Lobera, «El problema textual», en su edición de La Celestina en Biblioteca Clásica, pp. CCXXXIV, ss. 
del corrector, es justamente el arquetipo de $C$ y $D$, es decir, $x$. Y las tragicomedias no pudieron escribirse más que a partir de $x$. De manera providencial -por error o por una oculta intención-, el colofón de una edición de la Tragicomedia, impresa en Valencia, en $1514(P)$, en lugar de adaptar lugar y fecha al de cada nueva impresión, no trae la mención a la ciudad y al año en que se imprime, sino que, reproduciendo un modelo (¿el original, la edición Proaza?), certifica, como se lee más arriba, que este tratado fue impreso y acabado en Salamanca en el año de 1500.

Nada indica que, necesariamente, la edición burgalesa tuviera que ser anterior a la de Proaza ${ }^{12}$; queda, en todo caso, demostrado que es la única que no deriva de ella.

12. Como se sabe, el ejemplar único que se conserva en la Hispanic Society de Nueva York incluye, después del último folio una hoja en cuyo recto campea, en grabado, la marca del impresor (Fadrique de Basilea) y la fecha de 1499, todo ello no impreso sobre el papel originario, sino en facsimil moderno, lo que invalida la fiablidad de esta fecha para datar el año de la edición. Optamos, en un trabajo anterior, por datarla de modo provisonal en torno a 1500 (Cf. Sebastián Mediavilla, F. «Las primeras ediciones de La Celestina y su puntuación», p. 114). 